\title{
TRACHEOBRONCHIAL FOREIGN BODIES AT LIAQUAT UNIVERSITY HOSPITAL, HYDERABAD
}

\author{
Rais Uddin Siddiqui and M Rafique K K
}

\begin{abstract}
OBJECTIVE: To analyse presentation of tracheobronchial foreign body aspiration, their management and associated complications in our set up.

DESIGN: Descriptive study

SETTING: Department of Ear, Nose and Throat (ENT), Liaquat University Hospital Hyderabad, Sindh - Pakistan from January 2001 to December 2003.

METHODS: Medical records of 30 cases of foreign body aspiration in children and adult patients were retrospectively analyzed.

RESULTS: The highest incidence of foreign body aspiration was seen in children within ages of 2 to 5 years. Most of the cases were admitted in emergency with presentation as sudden attack of cough with a choking sensation followed by breathlessness with or without vomiting. In most of the cases radiographic confirmation was not seen but all cases undergone bronchoscopy. Removal of suspected foreign body from the tracheobronchial tree was done under general anesthesia using rigid bronchoscope with a telescope. In 29 cases, the foreign body aspiration was done without any complication. Beetle nuts were the commonest foreign body followed by plastic whistle seen impacted in the main bronchi.

CONCLUSION: The symptoms of an aspirated foreign body do not differ from the other pulmonary disorders, however, in the presence of positive history, no time should be spared to conduct the bronchoscopic examination and its removal to save the life of patient and minimize the complications.
\end{abstract}

KEY WORDS: Foreign Bodies. Aspiration. Management. Bronchoscopy.

\section{INTRODUCTION}

Foreign body aspiration is a serious and life threatening clinical disorder, especially in infants and young children. In our country, proper data is not available regarding the incidents, morbidity and mortality of this problem. In United States, almost 2.5 million children are affected each year and leading to an approximate 300 deaths annualy ${ }^{1}$. In another study from $U S A$, the annual death rate reported due to foreign body aspiration ranges from 500-2000 per year ${ }^{2}$. Meanwhile, a study conducted in Turkey has shown a high prevalence due to lack of parental attention and dietary habits ${ }^{3}$. In our society, use of chewing pan and beetle nuts is common in adults and the children incidentally swallow it. Moreover, playing with the plastic whistling toys is also common in children leading to foreign body aspiration in TracheoBronchial tree.

This study provides baseline information regarding presentation of tracheobronchial foreign body aspiration, their management and associated complications in our set up.

\section{PATIENTS AND METHODS}

During year 2001 to 2003, 30 cases of foreign body aspiration reported in Ear, Nose and Throat (ENT) Department of Liaquat University Hospital Hyderabad, Sindh - Pakistan. Majority of the cases were children. All the cases presented with the clinical history of foreign body inhalation. Twenty six of them were children and four were adults (above the age of 50 years). Medical records of these cases were analyzed according to gender, age, type and location of foreign body, presenting symptoms of the patient, radio-graphical findings and the complications. All the foreign body aspirations were done under general anesthesia using appropriate sized rigid bronchoscope (Karl-Storz-Germany) equipped with telescope. Alligator forceps were used for grasping and removal of the foreign body. In 27 cases, the removal of foreign body was done successfully, while in 2 cases foreign body thick mucus plug was aspirated out. But, in one case, the foreign body could not be removed at all, as it was a sweet toffee which dissolved during removal liberating honey like 
material. In this case, tracheostomy was performed for regular bronchial toilet post-operatively.

\section{RESULTS}

There were 18 male and 12 female patients with the ratio of 1.5:1. Twenty six patients were children up to the age of 10 years. More details regarding age of cases are presented in Graph I. The most frequent symptom was the sudden onset of intractable cough along with chocking sensation associated with or without vomiting and the wheezing. This is described as penetration syndrome ${ }^{4}$, and was present in 24 cases $(80 \%)$ while 6 patients $(20 \%)$ were admitted with breathlessness. Of these, 2 had progressive cyanosis and 2 were having strider. Radiographic findings are shown in Graph II and Figure I. The nature of foreign body was confirmed after its removal. Beetle nuts was removed in 15 patients, plastic whistle from 8 patients, metallic screw from 1 patient, coin and a plastic denture from 2 patients. From 1 case a broken wing of tracheostomy tube and from 2 cases, thick dry mucus plug seen blocking the bronchial tree was sucked out. In 1 case, sweet toffee dissolved during removal (Table I). In 17 cases, right main bronchus was the main site while in 8 cases, the foreign body was found in left bronchus. In 4 cases, it was at the level of carina and in 1 case, it was in the sub-glottis area (Figure II-IV).

All foreign body aspirations were done without any operative complication. Only in 1 case, tracheostomy was performed for the regular bronchial toilet.

\section{TABLE I}

\section{SHOWING TYPES OF FOREIGN BODIES $(n=30)$}

\begin{tabular}{|l|c|c|}
\hline Foreign Body & No. of Cases & $\%$ age \\
\hline Beetle nuts & 15 & 50 \\
\hline Plastic whistle & 08 & 27 \\
\hline Mucus Plug & 02 & 6.5 \\
\hline Screw (Metallic) & 01 & 3.3 \\
\hline Coin & 01 & 3.3 \\
\hline Wing/Tracheostomy Tube & 01 & 3.3 \\
\hline Denture & 01 & 3.3 \\
\hline Toffee & 01 & 3.3 \\
\hline
\end{tabular}

\section{DISCUSSION}

Foreign body aspiration is a life threatening condition. This can occur at any age group but its incidence is high in the pediatrics age groups ${ }^{5}$. In our study, majority of the cases (26) belonged to the ages of 1 to 10 years and the peak incidence was noted in children with 2 to 5 years of age. This corresponds to the study by Bharaloo $\mathrm{F}^{4}$, which also noted the highest incidence in this age group of children. The foreign body may lodge in the oral cavity, hypopharynx and produce airway obstruction/asphyxia but most of the time, it passes down through the larynx and involves the trachea or even the bronchi ${ }^{6}$. Severity of the symptoms and the airway obstruction depends upon the nature of foreign body and its site of impaction in the tracheobronchial tree $^{7}$. In children, usually a history of foreign body is present along with intractable cough and sudden chocking sensation. But in case of adults, it remains unnoticed and treated as a case of asthmatic exacerbation until and unless radiographic assessment confirms it $^{8}$. In our series of adult patients, a coin and a broken wing of tracheostomy tube was seen impacted in the right main bronchi and being treated as a case of bronchiectasis and pulmonary tuberculosis by pulmonologist. The nature of the foreign body inhaled depends upon the personal habitis and professions ${ }^{9}$. Children are at risk for putting small toys, candies and nuts into their mouth. Young children aged 1-3 years chew incompletely with incisors before their molars erupt, and objects of fragments may be propelled posteriorly, triggering a reflex inhalation. Among adults, impaired swallow reflex, impaired cough reflex, poor dentition, loss of consciousness and maxillofacial trauma facilitate foreign body aspiration ${ }^{5}$. Objects frequently aspirated include food, teeth, dental appliances and medical instruments. Radiographic confirmation of the inhaled foreign body depends upon their nature and type. Organic foreign body is radiolucent and does not visualize on the X-Rays, but it induces local inflammation, edema, ulceration and granulation formation contributing airway obstruction. Distal to the obstruction, air traffic leads to the local emphysema, atelactasis or bronchiectasis ${ }^{5}$. In our study, air trapping was seen in 16 cases, 7 cases showed bronchiectasis, and 4 cases the atelactasis. In all these cases, the foreign bodies were beetle nuts, plastic whistles or dentures, and only in 3 cases the radio-opaque foreign body was seen on radiography (Figures II-IV). In our series, the patient from whom the coin was removed was suffering with pulmonary koch's and being treated for that pathology previously. In one case a broken wing of tracheostomy tube was removed. Right main bronchus is the common site where the foreign body impaction occurs because of its vertical direction $^{9}$. In our series, foreign body was removed from right bronchus in 17 cases, from left bronchus in 8 cases, at the level of carina in 4 cases and 1 was 
seen in the subglottic area. In all suspected cases of foreign body aspiration, the bronchoscopy is the choice of treatment to reduce morbidity and mortality without any delay ${ }^{10}$. Rigid bronchoscope is still valuable for this purpose as compared to the flexible bronchoscope $^{11}$. In our series, all the cases underwent rigid bronchoscopy along with the telescope and the foreign body was removed successfully in 27 cases without any complication. Tracheostomy was done in only one case where the foreign body could not be gripped and dissolved during grasping. However, there were two cases mimicking as the case of foreign body but only the thick plug of mucus seen in the right and left bronchus.

Graph I showing age distribution of cases: $(n=30)$

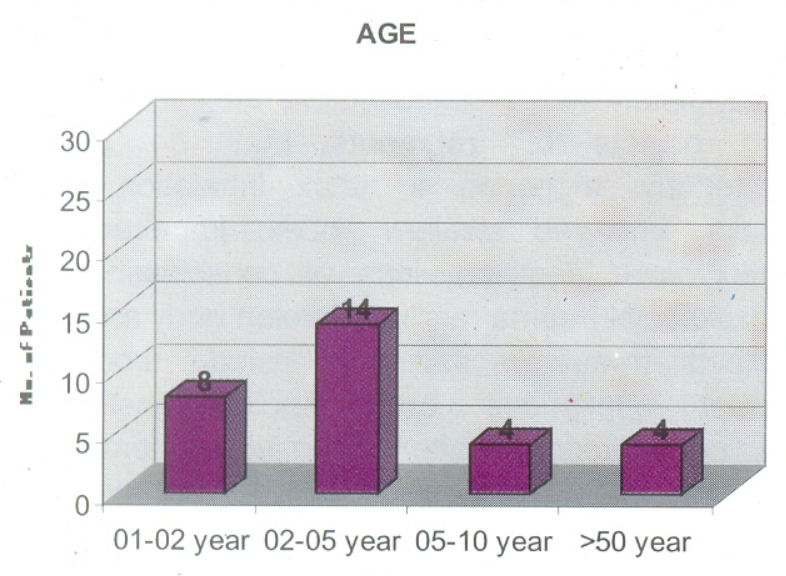

Graph II showing radiographic findings of the cases: $(n=30)$

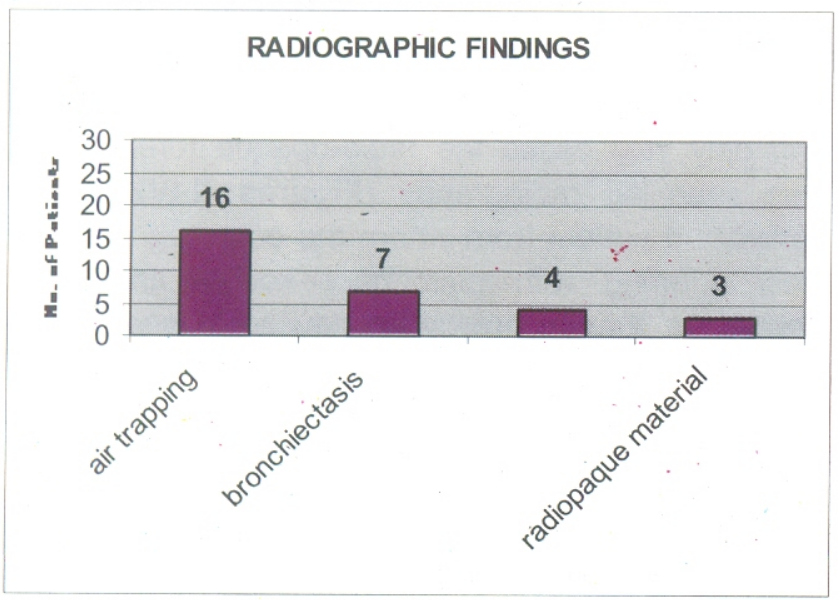

Figure I showing left lung atelactasis

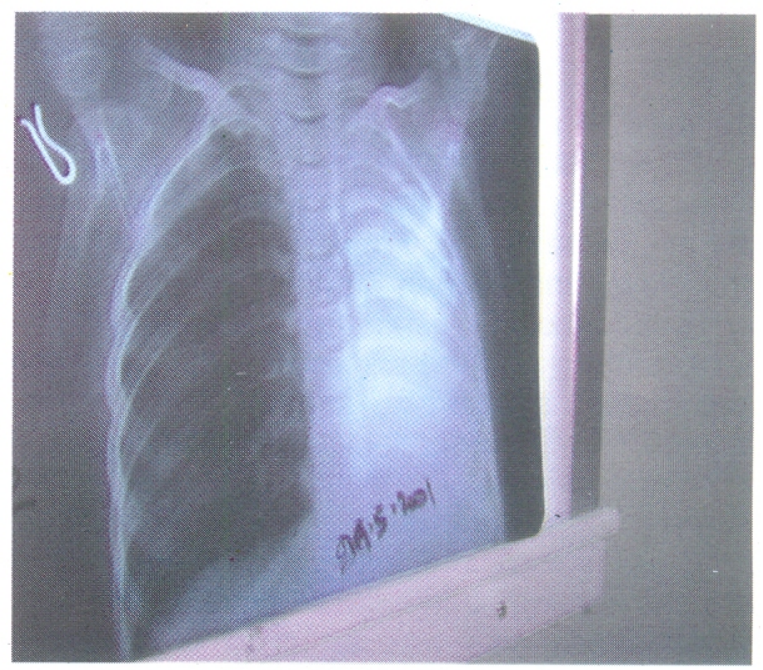

Figure II showing metallic screw in left bronchus

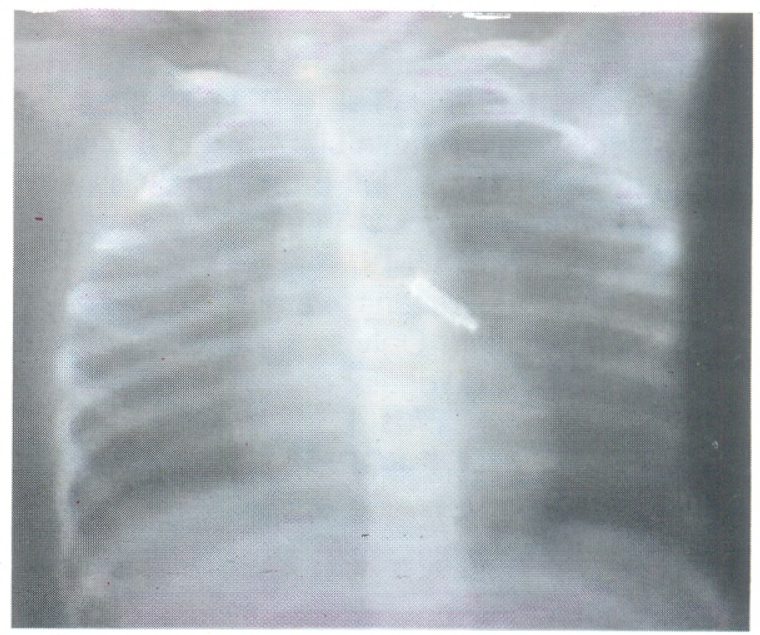

Figure III showing wing of tracheostomy tube in right bronchus

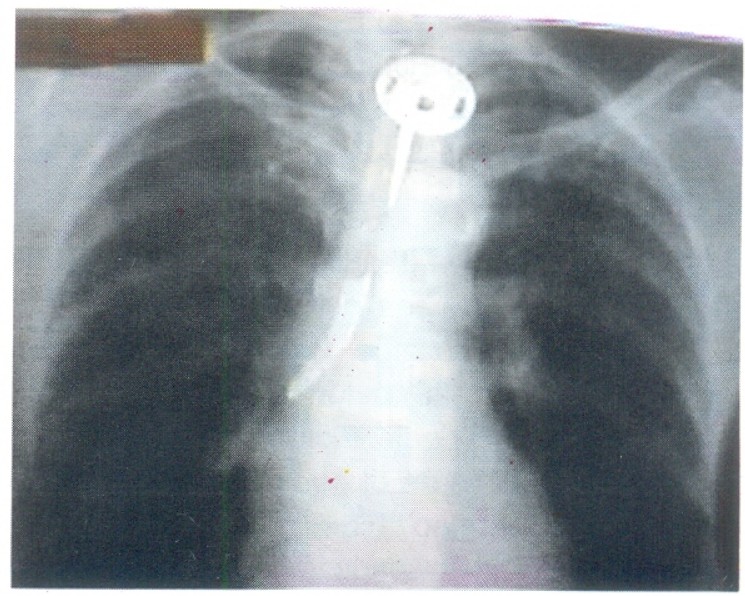


Figure IV showing coin in right bronchus

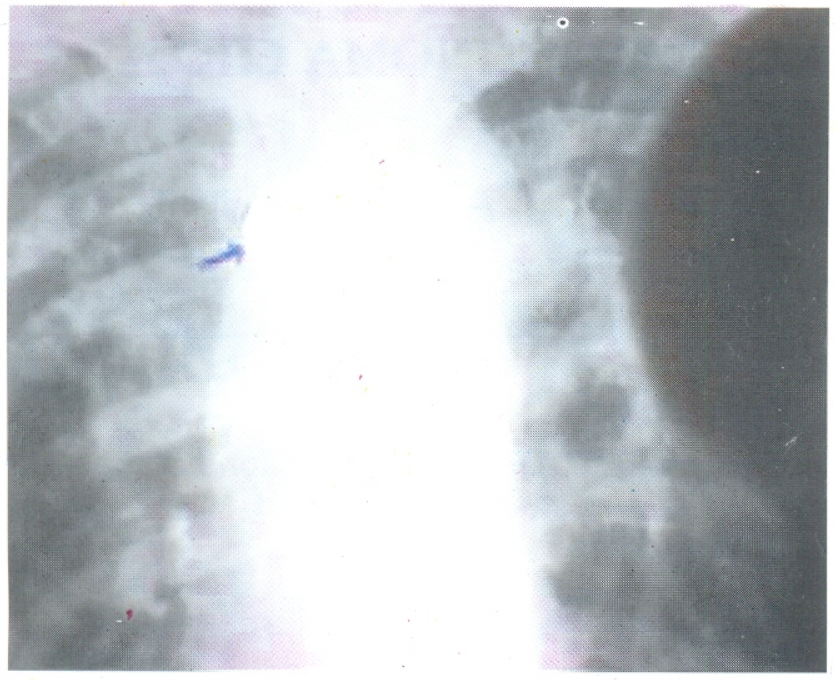

\section{CONCLUSION}

Tracheobronchial foreign body is a serious life threatening condition especially in children. The symptoms of an aspirated foreign body do not differ from the other pulmonary disorders, however, in the presence of positive history, no time should be spared to conduct the bronchoscopic examination and its removal to save the life of patient and minimize the complications. The complications usually depend upon the existing pulmonary infections and late presentation of the cases. Nature of foreign body and the duration of the procedure also contribute in the complications.

Moreover, an educational campaign is necessary in the society regarding the hazards of use of beetle nuts in adults and the parents need careful attention towards the children while they are playing with small toys.

\section{REFERENCES}

1. Salcedo L. Foreign Body Aspiration. Anaesthesiol Clin North Am 1998;16: 885-892.

2. Cohen SR, Herbert WI, Lewis GB et al. Foreign Body in the airways: Five Year Retrospective Study with special reference to Management. Ann Oto Rhinol Laryngol 1980; 89: 437-422.

3. Eroglu A, Kurkcuoglu IC, Karaoglanoglu $\mathrm{N}$ et al. Tracheobronchial Foreign Bodies: A 10 year Experience. Ulus Travma Derg 2003; 9 (4):262266.

4. Wiseman NE. The diagnosis of Foreign Body in childhood. J Pediatrics Surgery 1984 ;19: 531535.

5. Baharloo F, Veyckemans F, Francis $C$ et al. Tracheobronchial Foreign Bodies: Presentation and Management in Children and Adults. Chest 1990; 115: 1657-1362

6. Johnson DG, Conodon VR. Foreign Bodies in Pediatric Patients. Curr Surgery 1998; 35: 278332.

7. $\mathrm{Mu}$ L, He P, Sun D. Inhalation of Foreign Bodies in Chinese children. A review of 400 cases. Laryngoscope 1991; 101: 657-660.

8. Kaur K, Sonkhya N, Bapna AS. Foreign Bodies in Tracheobronchial tree: A prospective study of fifty cases. Indian J Otolaryngology Head Neck Surgery 2002; 54(1): 30-35.

9. Steen $\mathrm{KH}$, Zimmermann T. Tracheobronchial aspiration of Foreign Bodies in Children. A study of 94 cases. Laryngoscope 1990: 100: 525-535.

10. McGuirt WF, Holmes KD, Feehs $R$ et al. Tracheobronchial Foreign Bodies. Laryngoscope 1988; 98: 615-614.

11. Emir H, Takent G, Basik C et al. Bronchoscopic removal of Tracheobronchial Foreign Bodies: Value of patient history and timing. Paeds Surgery Int 2001; 17(2-3): 85-87.

AUTHOR AFFILIATION AND CORRESPONDENCE ADDRESS:

Dr Rais Uddin Siddiqui (Corresponding Author)

Assistant Professor, Department of Ear Nose Throat (E.N.T), Liaquat University Of Medical \& Health Sciences (LUMHS), Jamshoro, Sindh, Pakistan. Tel: 0300-8371168 Email: rais_ent@ hotmail.com

Dr. M Rafique K.K

Senior Lecturer, ENT, LUMHS, Jamshoro, Sindh, Pakistan. 